of the slow pressor effect is particularly elusive. No significant changes in plasma catecholamine concentrations or in renin activity were found after four days of alcohol, though $\alpha$ adrenergic responsiveness decreased, which would suggest that sympathetic activity was set at a higher level after alcohol. ${ }^{15} \mathrm{~A}$ direct vasoconstrictor effect of alcohol has been postulated, though in most vascular beds this is seen only at near lethal concentrations. ${ }^{19}$ Alcohol withdrawal hypertension is more clearly linked with pressor substances, and clinically the syndrome resembles a heightened sympathetic state. Plasma noradrenaline concentrations, renin activity, and concentrations of aldosterone and cortisol are raised during withdrawal, though only cortisol concentration correlates significantly with blood pressure..$^{20}$ Whether a subclinical withdrawal state explains the association in population studies remains conjectural; but as raised blood pressure is seen in those apparently having only one to two drinks daily this is less likely than was previously thought. ${ }^{910}$

The exact mechanisms need not overly concern us. The practical message is clear: alcohol is an important risk factor for hypertension, and in $10-30 \%$ of cases it may be the principal or sole cause. By predisposing to cerebrovascular events alcohol related hypertension is an important cause of morbidity and mortality ${ }^{21}$ and may accentuate the direct effects of alcohol on morbidity from stroke..$^{22}$ It is largely and promptly reversible when alcohol is stopped or substantially reduced, at least in the early stages. It is also often unrecognised. Every hypertensive patient should be asked about his or her drinking habits. Advice and help to reduce to one drink $(10 \mathrm{~g})$ of alcohol daily and preferably less (or to abstain if the patient is alcohol dependent) are essential.

JOHN B SAUNDERS

Staff Specialist Physician,

Department of General Medicine and

Drug and Alcohol Services,

Royal Prince Alfred Hospital,

Sydney,

NSW 2050,

Australia

1 Klatsky AL, Friedman GD, Siegelaub AB, Gerard MJ. Alcohol consumption and blood pressure. Kaiser-Permanente multiphasic health examination data. $N$ Engl f Med 1977;296:1194-200.

2 Ramsay LE: Liver dysfunction in hypertension. Lancet 1977;ii:111-4.

3 Beevers DG. Alcohol and hypertension. Lancet 1977;ii:114-5.

4 Dyer AR, Stamler J, Paul O, et al. Alcohol consumption, cardiovascular risk factors, and mortality in two Chicago epidemiologic studies. Circulation 1977;56:1067-74.

5 Mathews JD. Alcohol use, hypertension and coronary heart disease. Clin Sci 1976;51:661s-3s.

6 Lian C. L'alcoolisme, cause d'hypertension arterielle. Bull Acad Natl Med 1915;74:525-8.

6 Lian C. L'alcoolisme, cause d'hypertension arterielle. Bull Acad Natl Med 1915;74:525-8.
7 Dawber TR, Kannel WB, Kagan A, Donabedian RK, McNamara PM, Pearson G. Environmental factors in hypertension. In: Stamler J, Stamler R, Pullman T, eds. The epidemiology of hypertension. New York: Grune and Stratton, 1967:255-8.

8 Shah VV. Environmental factors and hypertension with particular reference to the prevalence of hypertension in alcohol addicts and teetotallers. In: Stamler J, Stamler R, Pullman T, eds. The epidemiology of hypentension. New York: Grune and Stratton, 1967:204-18.

9 Saunders JB, Beevers DG, Paton A. Factors influencing blood pressure in chronic alcoholics. Clin Sci 1979;57:295s-8s.

10 Saunders JB, Beevers DG, Paton A. Alcohol-induced hypertension. Lancet 1981;ii:653-6.

11 Arkwright PD, Beilin LJ, Rouse I, Armstrong BK, Vandongen R. Effects of alcohol use and other aspects of lifestyle on blood pressure levels and prevalence of hypertension in a working population. Circulation 1982;66:60-6.

12 Klatsky AL, Friedman GD, Armstrong MA. The relationships between alcoholic beverage use and other traits to blood pressure: a new Kaiser-Permanente study. Circulation 1986;73:628-36.

13 Potter JF, Beevers DG. Pressor effect of alcohol in hypertension. Lancet 1984;i:119-22.

14 Malhotra H, Mehta SR, Mathur D, Khandelwal PD. Pressor effects of alcohol in normotensive and hypertensive subjects. Lancet 1985;ii:584-6.

15 Howes LG, Reid JL. Decreased vascular responsiveness to noradrenaline following regular ethanol consumption. Brf Clin Pharmacol 1985;20:669-74.

16 Puddey IB, Beilin LJ, Vandongen R, Rouse IL, Rogers P. Evidence for a direct effect of alcoho consumption in normotensive men: a randomised controlled trial. Hypertension 1985;7:707-13.

17 Puddey IB, Beilin LJ, Vandongen R. Effect of regular alcohol use on blood pressure control in treated hypertensive subjects-a controlled study. Clin Exp Pharmacol Physiol 1986;13:315-8.

treated hypertensive subjects-a controlled study. Clin Exp Pharmacol Physiol 1986;13:315-8.
18 Puddey IB, Beilin LJ, Vandongen R. Regular alcohol use raises blood pressure in treated hyddey IB, Beilin LJ, Vandongen R. Regrive subjects. Lancet (in press).
hypenste

19 Howes LG, Reid JL. The effects of alcohol on local, neural and humoral cardiovascular regulation. Clin $S c i$ 1986;71:9-15.

20 Bannan LT, Potter JF, Beevers DG, Saunders JB, Walters JRF, Ingram MC. Effect of alcohol withdrawal on blood pressure, plasma renin activity, aldosterone, cortisol and dopamine beta hydroxylase. Clin Sci 1984;66:659-63.

21 Kozarerevic D, McGee D, Vojvodic N, et al. Frequency of alcohol consumption and morbidity and mortality. The Yugoslavia cardiovascular disease study. Lancet 1980;i:613-6.

22 Gill JS, Zezulka AV, Shipley MJ, Gill SK, Beevers DG. Stroke and alcohol consumption. N Engl f Med 1986;315:1041-6.

\section{Antenatal, perinatal, or postnatal brain damage?}

Environmental factors have been important in the consistent fall in perinatal mortality over the past 30 years, but so probably has fetal monitoring, which has reduced intrapartum deaths and increased the chances of the paediatrician keeping the infant alive. Survival and damage have been assumed to run in parallel: if you kept more infants alive necessarily there would be fewer spastic infants. Unfortunately, this does not seem to be the case.

As far back as 1974 Brown drew attention to the fact that birth asphyxia was common but asphyxial brain damage rare. ${ }^{1}$ Only 17 of 760 severely asphyxiated infants developed cerebral palsy, and, though neonatal death was a common concomitant of severe fetal hypoxia, survival with brain damage was uncommon. This should be reassuring in some ways, but it is not. Dweck et al studied 15 children severely asphyxiated at birth, and with the exception of three infants who showed intrauterine growth retardation they did not have an impaired intelligence quotient or motor development at later assessment. ${ }^{2}$ Their study does suggest, however, that severe perinatal asphyxia is associated with brain injury if the fetus shows intrauterine growth impairment. Other studies on the antecedents of cerebral palsy ${ }^{3}$ have shown that including information about the events of birth and the neonatal period allows only a marginally better prediction of outcome than information gathered before labour begins. In other words, what happens before labour is much more important than what happens during and after labour.

Cordocentesis has shown that many infants with intrauterine growth retardation have an impaired acid base state before birth. In the study by Soothill et al (p 1051) 10 of 38 infants with growth retardation had blood $\mathrm{pH}$ values below the $95 \%$ confidence limits for normal infants. If we assume that the procedure itself did not selectively differentiate between normal fetuses and those with growth retardation then the observation has considerable implications for obstetrics.

Firstly, it draws attention to the need to develop better techniques to assess the fetal brain and cardiovascular system in utero. Fetal acidosis may be secondary to abnormalities in the brain, but if we assume that the reverse is true then impaired placental function results in defective gaseous transfer-and such a disorder could be corrected. The study also raises the question about how long and how severe changes in fetal acid base state and fetal oxygenation need to be before important impairment of cerebral function occurs. Cordocentesis is unlikely to prove to be practicable for diagnosing prenatal asphyxia routinely because of the technical risks and the timing difficulties. There is, however, the possibility of developing non-invasive and repetitive techniques that would achieve diagnostic precision in prenatal diagnosis of fetal hypoxia.

Secondly, the law courts have increasingly assumed that any infant who develops cerebral palsy must have been damaged by intrapartum mismanagement. The obstetrician is pressured towards earlier intervention if the fetus shows any signs of hypoxia for fear of litigation should the child prove to have abnormal cerebral function. Soothill et al's study highlights the fact that much may happen before the onset of labour even if parturition makes matters worse.

A technique that could accurately diagnose fetal hypoxia 
might free the obstetrician from the unwanted attention of the lawyers in these matters.

Professor of Obstetrics and Gynaecology,

E M SYMONDS

University Hospital,

Nottingham NG7 2UH

1 Brown JK. Infants damaged during birth: pathology. In: Hall D, ed. Recent advances in paediatrics. New York: Churchill Livingstone, 1976:35-88.

2 Dweck $H$, Huggins $W$, Dorman $L$, et al. Developmental sequelae in infants having severe perinatal asphyxia. Am f Obstet Gynecol 1974;119:811.

Nelson KB, Ellenberg JH. Antecedents of cerebral palsy. N Engl f Med 1986;315:81-6.

\section{Screening for congenital dislocation of the hip}

Unlike many examinations carried out in child health surveillance programmes, screening for congenital dislocation of the hip cannot be said to be unresearched. A selective Medline search provided over 100 papers on the screening, diagnosis, and management of the condition. From the past six years they show that the early identification of the 15-20 children in 1000 at high risk of having instability and subluxation, dysplasia, or both, of the hip joint is of great benefit to the two to four (and perhaps more) of them who would go on to suffer the long term consequences if not treated. Workers dedicated to identifying congenital dislocation of the hip who have good back up services can identify $80-90 \%$ of all the cases in the population in the first six weeks of life. Under these conditions the selectivity, sensitivity, and cost effectiveness of the test are acceptableanything less and the programmes fail. ${ }^{2}$ So the important question is not whether to set up a screening programme but how to set up one that is effective.

This important question has been partly answered by a revised version of the government handbook Screening for the Detection of Congenital Dislocation of the Hip. ${ }^{3}$ It is an excellent review of current thinking, and a doctor ignores it at his peril. The handbook is concerned only with screening and offers no advice on management. It is directed specifically at those organising and running child health surveillance programmes and those carrying them outmidwives, paediatricians, obstetricians, health visitors, general practitioners, and clinical medical officers. More's the pity that all these groups did not receive a free copy: it went to most of the doctors but not to most of the nurses. Why not?

The most important section is on who should do the screening. The district health authority should have a policy outlining who is responsible for examining for congenital dislocation of the hip at various stages and should appoint a designated officer to review the whole programme. Several health professionals may at some time have to examine a child's hips, and they should all be proficient-therefore training is crucially important.

The handbook discusses future developments; and ultrasound may well be used much more in diagnosis. It looks good from the little research done so far, especially as it is non-invasive and its results are sensitive. Also clinically normal but dysplastic hips do probably exist, and ultrasound may be able to detect them. ${ }^{4}$ Further research must therefore be funded into using ultrasound both for initial screening and for secondary screening of those children already identified as being at high risk. These would include those with a clicking or dislocatable hip and those with some other risk factor such as a family history of the condition, other congenital postural deformities, or a history of breech presentation, caesarean delivery, oligohydramnios, or severe fetal growth retardation.

For now, however, the screening programme for congenital dislocation of the hip must be that outlined in the handbook, and the next step has to be taken by those responsible for the child health surveillance programmes in the districts. If the suggestions are not already operational and they do not intend to make them so but have the funding they will need to think up a good excuse rapidly.

AIDAN MACFARLANE

Consultant Paediatrician with special interest in

community child health and Clinical Lecturer in Paediatrics, District Department of Community Medicine,

Radcliffe Infirmary,

Oxford OX2 6HE

1 Dunn PM. Screening for congenital dislocation of the hip. In: Macfarlane A, ed. Progress in child health. Vol 3. London: Churchill Livingstone, 1986:1-12.

Hanssen G, Nachemson S, Palmen K. Screening of children with congenital dislocation of the hip Hanssen G, Nachemson S, Palmen K. Screening of children with congenita
joint on the maternity wards in Sweden. J Pediatr Orthop 1983;3:271-9.

3 Standing Medical Advisory Committee and Standing Nursing and Midwifery Advisory Committee for the Secretaries of State for Social Services and $W$ ales. Screening for the detection of congenital for the Secretaries of State for Social Services and Wales. Screening for the detection

4 Berman L, Klenerman L. Ultrasound screening for hip abnormalities: preliminary findings in 1001 neonates. BrMed J 1986;293:719-22.

\section{More evidence on unemployment and health}

Most of those who have studied the future of employment agree that whichever political party is in power the total amount of employment is going progressively to diminish. ${ }^{12}$ A generation ago people expected to be employed over a lifetime for 100000 hours (47 hours a week for 47 weeks a year for 47 years), but already it is down to 50000 hours (37 hours a week for 37 weeks a year for 37 years). Soon it will be less. This means that we either share out more the employment available or we have an ever growing number of unemployed. It also means that unemployment is not going to be spirited away by either a statistical or a political sleight of hand. Researchers therefore need to continue to w/: rk to increase our limited understanding of how unemployment affects health, and health workers and health authorities need to think more creatively about how they can respond to the problem. Three papers that we publish this week and one that we published earlier in the year should help.

The earlier paper by Moser et al (10 January, p 86) has not had the attention that it deserves. Their earlier study from the 1971 census had shown that men seeking work at the time of the census had had a significantly higher mortality over the next 10 years than men in work. ${ }^{3}$. The authors were confident that the excess mortality was caused by unemployment itself and had not arisen simply because sick men were more likely to be unemployed. But in 1971 unemployment was well under a million in Britain, and the authors warned that it would be wrong to extrapolate their findings to now when unemployment is around three million. It was in 1979 that unemployment began to rise very steeply in Britain, and by 1981 the figure was similar to that now. Thus the author's new findings that their results from the 1981 census are 